\title{
Design and simulation of a microgrid for TIH campus
}

\author{
Zaid H. Ali ${ }^{1}$, Ziyaad H. Saleh ${ }^{2}$, Raid W. Daoud ${ }^{3}$, Ahmed H. Ahmed ${ }^{4}$ \\ ${ }^{1,3,4}$ Hawija Technical Institute (HTI), Northern Technical University (NTU), Iraq \\ ${ }^{2}$ Department of Petroleum system control Engineering, Tikrit University, Iraq
}

\begin{tabular}{l}
\hline \hline Article Info \\
\hline Article history: \\
Received Jan 10, 2019 \\
Revised May 1, 2019 \\
Accepted Jul 1, 2019
\end{tabular}

Keywords:

Droop controllers

Energy storage systems

Microgrids

PV generation systems

\begin{abstract}
This paper proposes a methodology for designing and operating a microgrid (MG) for the main campus of the Technical Institution Hawija. In this MG, a battery energy storage system (BESS), photovoltaic (PV) generation system, and controllable loads are included. Due to the high penetration of the PVs, over-voltage issues may occur in this MG. A novel operation strategy is considered by coordinating the BESS, PVs, and loads to prevent power outages and accomplish a secure operation of this MG. In this proposed approach, droop controllers have been implemented to provide the appropriate references for the PVs and BESS to maintain the voltage of the MG within a secure range. The generation of the PVs may be curtailed to guarantee the fidelity of the voltage. The intended simulations will be based on MATLAB/Simulink to show the efficacy of the intended design.
\end{abstract}

Copyright $\odot 2020$ Institute of Advanced Engineering and Science. All rights reserved.

\section{Corresponding Author:}

Zaid H. Ali,

Electrical Department Technique,

Northern Technical University, Kirkuk.

Email: zaid.ali@uconn.edu

\section{INTRODUCTION}

There have been many studies on building campus MGs which studied proposed ways to control over voltage issues due to high penetrations Distribution Generators (DG). [1] presented a model MG with different generators such as solar cells, wind generators, and fuel cells over the distributed grid. The authors gave some information about the DGs and devices needed to couple sources with the grid to coordinate the power supplied from DGs. The simulation gave a clear image how the voltage and frequency of all DGs were synchronized. Other work studied integration of renewable energy and storage system with the distribution network looking at on the voltage profile impact at several points, Islanding effect on critical loads was discussed [2]. In [3] university campus comes with the diffirent type of DGs to meet diffirent kinds of loade demand such as heat,air conditioing,and elctricity. A design of general system was presented for a university campus MG which studied the proposed design, modeling and optimal operation of a campus MG. The purpose of the optimal operation is to reduce PV system costs in exchange with the local electrical gird. The authors stated equations expressed how to achieve a power balance in the system [4]. Another study investigated a method to control the voltage and its frequency during islanding mode. The loads observed required real and reactive powers under various operation conditions to maintain control of frequency and voltage. The following control strategies were introduced: real and reactive control strategy, real and reactive power constraint, real power priority constraint, and PF-QV control strategy [5-6]. A different study of MG design included designing a visualization tool to explain the result of sizing of RES and its effectiveness under various loads and bring attention of operators to where the power is generated and consumed [7]. A droop controller based on active power curtailment on preventing the overvoltage on the LV side due to the high penetration of PV systems was proposed. The result explained the effect of droop based active power curtailment design and the option to share power reduction among all customers [8]. An on-line control strategy to prevent over voltage due to high PV system penetrations was presented in [9]. The proposed method relied on accurate predictions of active power from PV systems by using the thevenin 
equivalent. A droop controller was used to curtail the predicted power to keep the terminal voltage within in range. In this method, the inverters did not shut down the PV systems and did not cause interruptions as in traditional overvoltage. Therefore, the proposed online voltage prevention method allowed a PV array to always stay online in the microgrid, generating a maximum allowable amount of energy without trip off voltage protection due to overvoltage[10]. The proposed work made communication between the controllers by active inverters for support in the form of consuming reactive power and reduced the active power curtailment as much as possible. It made a priority of the using reactive power, while active power reduction was performed as the last option to overcome overvoltage issues. Local voltage regulation in LV distribution networks with PV distributed generation studied in [11-12]. The integrated controller adjusted real power produced by a PV array according to voltage nodes. The controller could be a switch from one mode to other based on grid operation. The microgrid is constituted of energy sources, storage devices and loads. It is operated in two modes grid-connected mode and islanded mode [13]. The Microgrid complexity is usually occurred with flexible modes of operation and use of storage devices integration [14-16]. Several algorithms are presented to decrease Microgrid components [17-19]. The authors used a nonlinear droop controller to improve the control effect of droop control. the fluctuations reduction in the transient process and enhance stability has been done by changing the droop coefficient [20-22]. The authors used the master-slave control strategy, which is a multi-main power control method based on voltage and frequency[23]. The micro-grid stability operation can be done the raise the distribution accuracy of the reactive power [24]. The authors used an $\mathrm{f}-\mathrm{P} / \mathrm{Q}$ droop control scheme to improve power balance under different types of loads [25].

This paper is divided into the introduction and research method which details the MG components, such as PV systems, controllers, and storge. Also, reasarch and analysis that provides modulation of campus MG and its component with presenting results and discussion of modeling. MATLAB / SIMULINK was used to show the effecativness of the proposed method. The paper ends with concludes the research work comparing it with other results.

\section{RESEARCH METHOD}

The Hawija Technical Institution campus is located in Hawija-Kirkuk- Iraq and it is powered with $11 \mathrm{kV}$ by the National Company. The campus consists of several buildings utilized for different purposes which includes laboratories, a library, classrooms, and a gym. A transformer in each building will be used to step down the voltage from $11 \mathrm{kV}$ to $380 \mathrm{~V}$.

The campus load demand has been calculated to make sure the MG could handle load demand, especially during its peak. Second, to upgrading the campus grid to be a MG, three $500 \mathrm{KW}$ PV systems have been integrated on the low side voltage of the campus distribution grid based on calculated demand. One 500 KVA li-ion battery energy storage system has been integrated into the power grid. The MG diagram of HIT's main campus is shown in Figure 1. PV and storage systems have been well-appointed with controllers to fitting voltage and frequency within national grid.

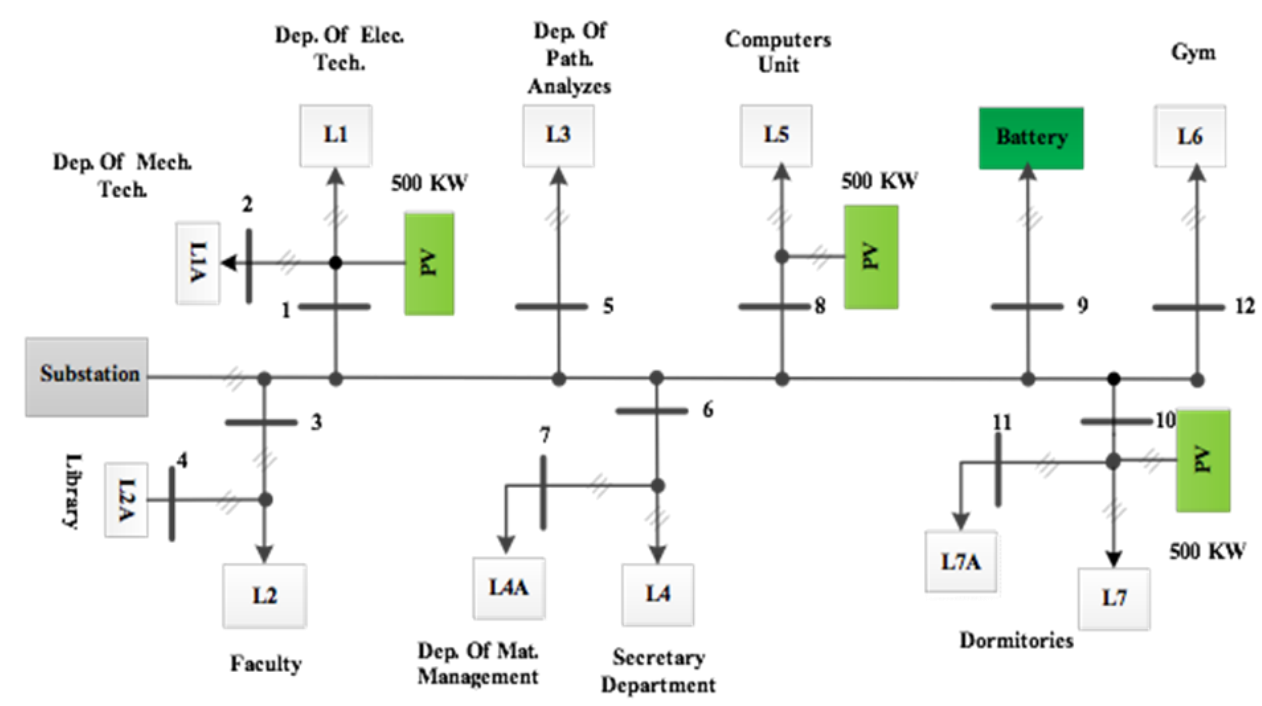

Figure 1. MG diagram of HIT's main campus 


\subsection{Operation scenarios}

a) Grid-connected mode: Grid-connected operation implies that the microgrid is works together with the main grid to exchanges power with it to cover load demand.

b) Islanding mode: implies that the microgrid is works independently to afford the demand power for the campus.

Tables 1 and 2 explain the power flow in the MG under specific conditions of load demand, PVs generations, and charge state of the battery.

Table 1. Status of power generation sources

\begin{tabular}{ccccc}
\hline & \multicolumn{4}{c}{ Status } \\
\hline Power Source & {$[\mathrm{a}]$} & {$[\mathrm{b}]$} & {$[\mathrm{c}]$} & {$[\mathrm{d}]$} \\
Grid & & & & $\sqrt{ }$ \\
PV & $\sqrt{ }$ & & & \\
Storage system & & & $\sqrt{ }$ \\
PVs \& Grid & & $\sqrt{ }$ & & \\
\hline
\end{tabular}

Table 2. Description status of power generation sources

\begin{tabular}{cc}
\hline Status & Description \\
\hline [a] & When campus load demand can be covered by PV generation. \\
[b] & When the PVs generation is not enough to cover load demand, \\
and there is no storge
\end{tabular}

\subsection{Droop controller molding}

The Droop Controller model was actualized to supply suitable references for the Storage system to preserve the voltage of the MG within a security extend from 0.95 to $1.05 \mathrm{pu}$. The droop controller was designed based on the following equations:

$$
(\text { Vref }- \text { Vbus }) \cdot m+P_{\text {ref }}=P_{\text {proposed }}
$$

where $V_{r e f}$ is the voltage reference, $V_{b u s}$ is the local voltage $m$ is the droop factor, $P_{\text {ref }}$ is the power set point reference, and $P_{\text {proposed }}$ is the power reference of the battery's inverter. Figure 2 is explained the proportional relationship between voltage and power. The figure shows the voltage was controlled by the referenced active power through setting an appropriate droop factor.

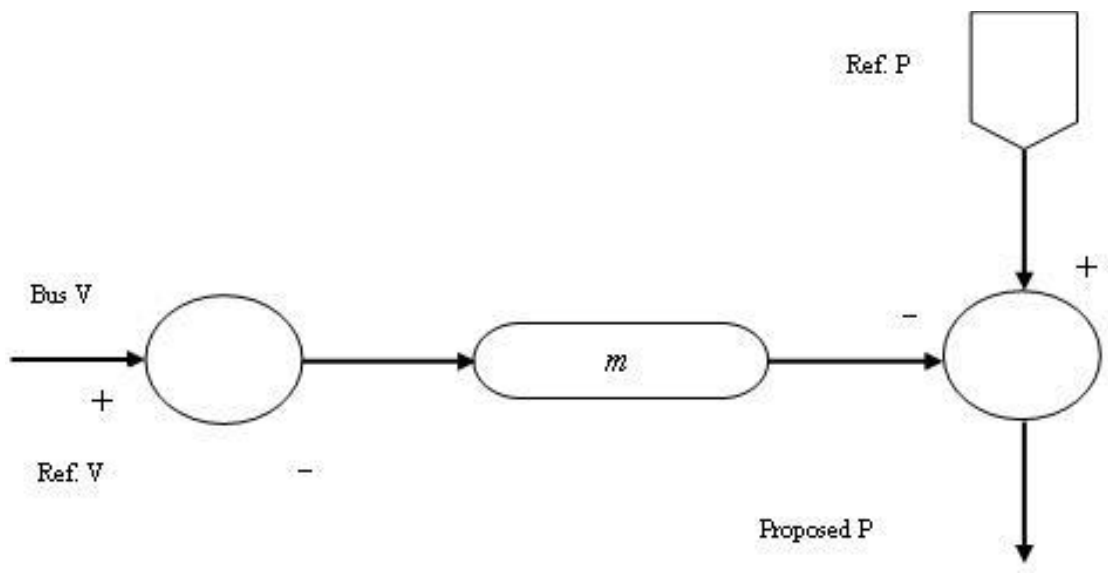

Figure 2. Voltage droop controller

\subsection{Management of the energy storage and the load demand}

The flow chart in Figure 3 explicates the process to prevent overvoltage issues by the management of BESS and PVs. The voltage of the battery bus is measured and compared with the reference value $(1.02 \mathrm{pu})$. If the measured voltage is less than $1.02 \mathrm{p} . \mathrm{u}$, the BESS would be in normal operation, either being charged or discharged based on its SOC. However, if the measured value is above the reference, the battery charges to absorb the surplus power based on the measured voltage at the battery's bus. The droop controller calculates the reference of the battery depending on the variation of voltage. In case of the battery having been fully charged, that is SOC 95\%, the power of PVs is curtailed by using a droop controller, just as it is for BESS. The droop controller of BESS is activated when overvoltage reaches $1.02 \mathrm{p} \mathrm{u}$, while droop controllers of the PVs are activated when overvoltage reaches $1.05 \mathrm{p} \mathrm{u}$. 


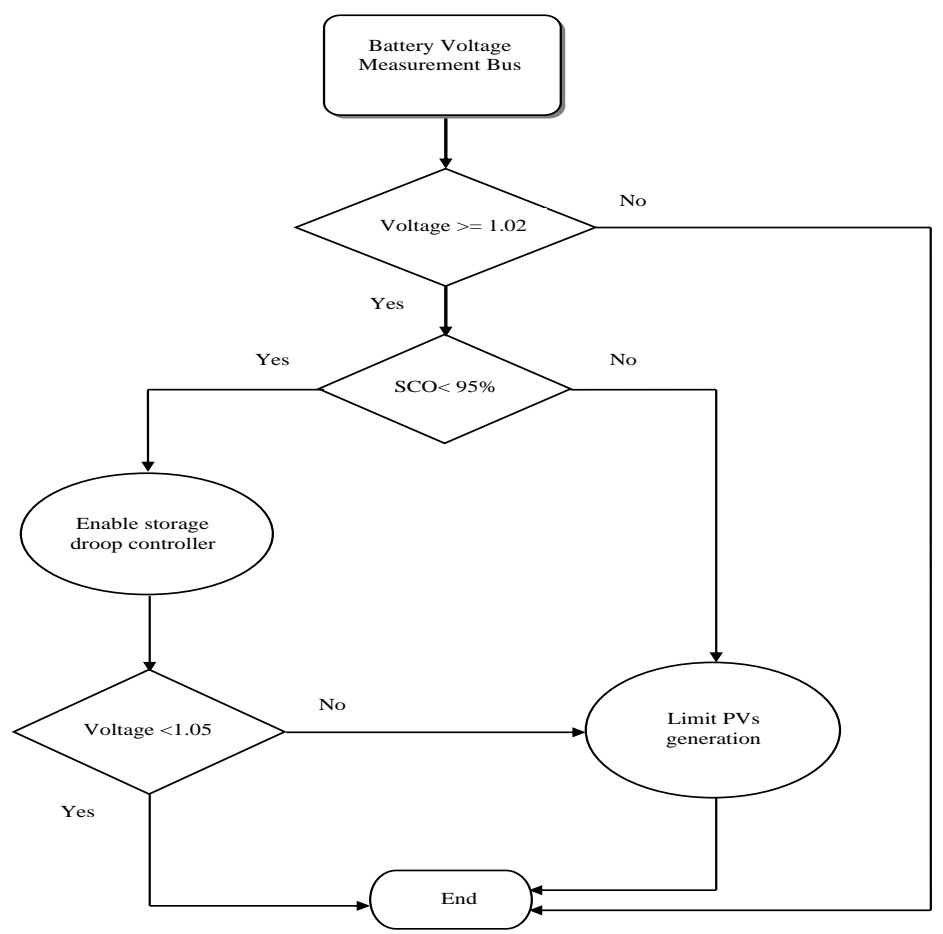

Figure 3. Eenergy storage and the load demand schematic

\section{RESULTS AND ANALYSIS}

This section illustrates the validation of secure operation and describes the performance of HTI's MG modeled and simulated in Section 2. The performance of the droop controller integrated with the storage system provides an appropriate reference for the storage system to observe required power. Thus, overvoltage due to high penetrations of the PV systems was prevented. Preventing overvoltage by curtailing active power of PVs in cases of saturated batteries was in fact verified. Dynamic simulations carried out with MATLAB/Simulink demonstrated that at the MG was connected to the grid where the voltage at the substation and PV systems were set up to be 1 pu. The MG was tested under varying solar irradiance. Figure 4 represent the system diagram.

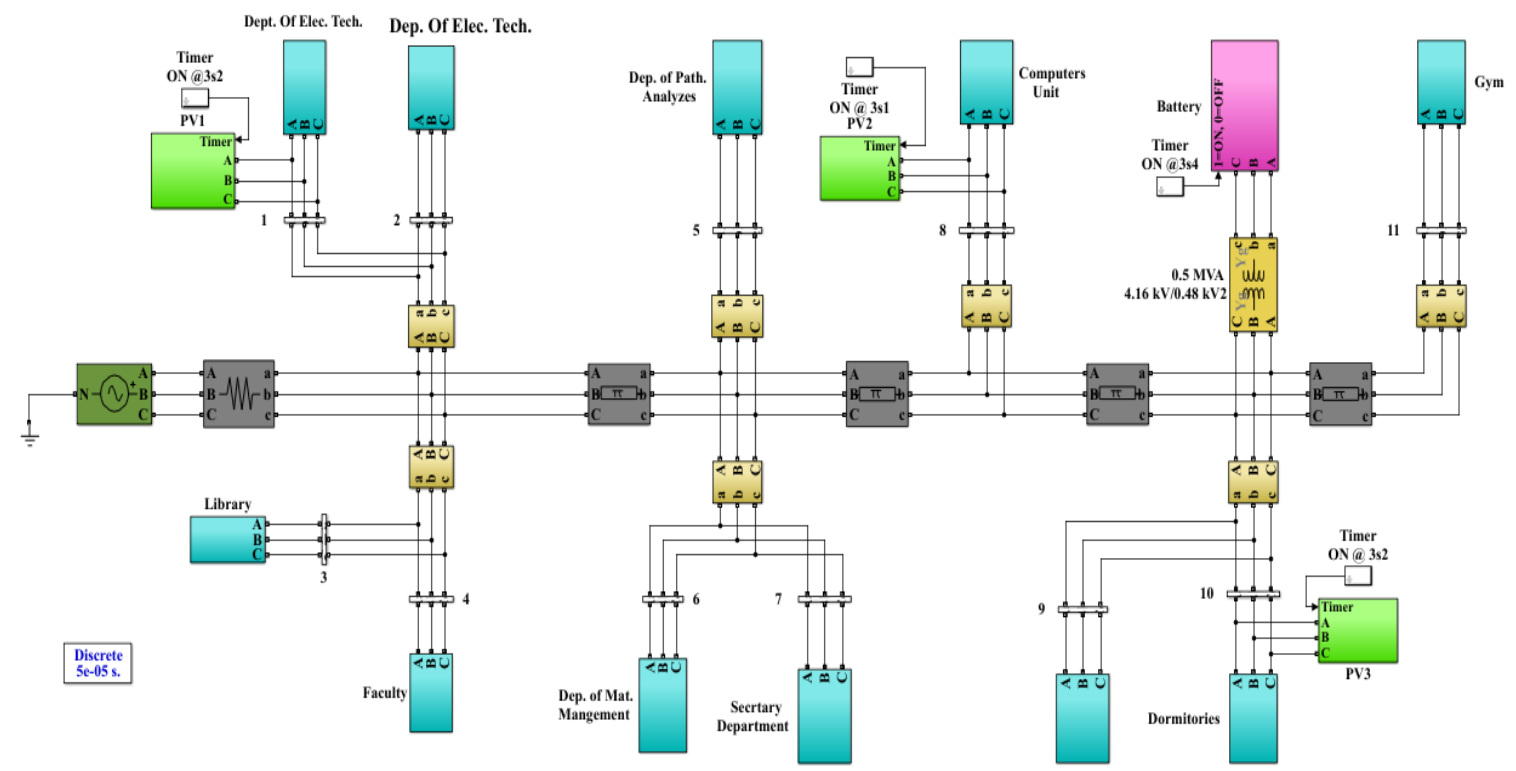

Figure 4. MG model of Hawija campus 


\subsection{PV systems generation}

To determine the performance of the new strategy that was mentioned in above a variant solar irradiation was tested due to the changing climate of the area surrounding the HTI. The goal was to avoid technical problems due to a lack of power generation or surplus power generation from PV systems. As shown in Figure 5, the output power was generated at various levels due to variant solar irradiation. Thus, the generation of the PV systems under variant weather conditions was verified.

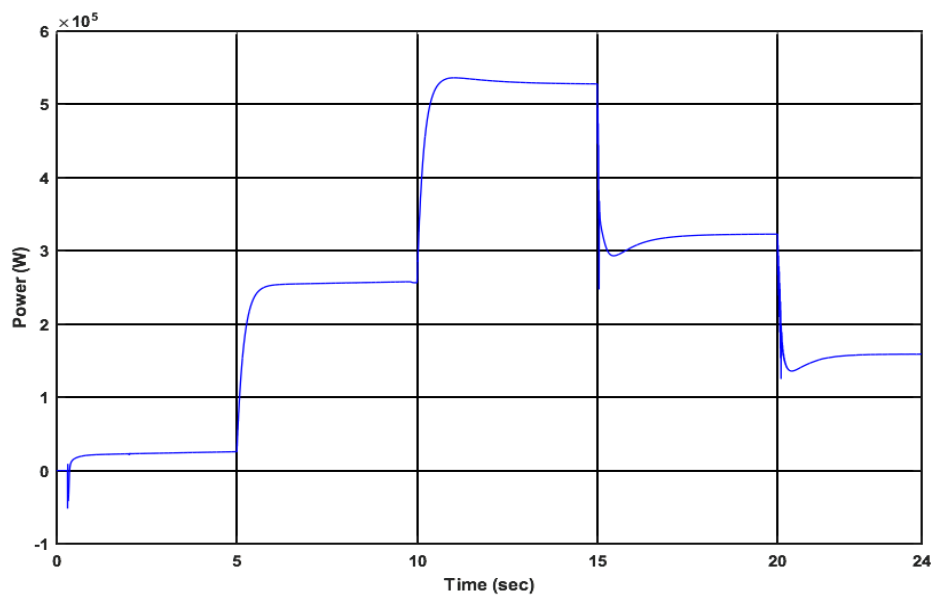

Figure 5. PV system output under variant solar irradiance

\subsection{Storage system}

While the PV systems generated the power for the MG, BEES was used to support the MG, but in the case of a lack of PV generations, and during the peak demand of the HTI camps. The simulation ran for 24 seconds and the BES was enabled at 3 seconds. The BES output rate reached $500 \mathrm{kVA}$ at 20 seconds as shown in Figure 6 . The output power of the battery was controllable with a constant rate for 24 hours (scaled to 24 seconds as shown Figure 6 to reduce the simulation time). Thus, the output power of the BESS was successfully integrated into the HTI's MG.

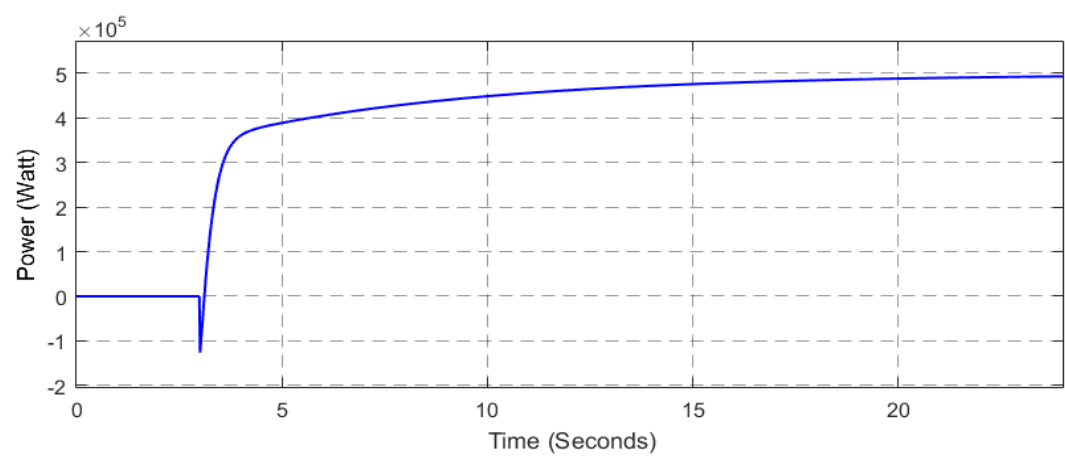

Figure 6. Output power of the battery under a normal case

\subsection{Total load demand of UNH}

The BESS would provide the power to the loads of HTI, in the case of a lack of PV generation. The total load demand representing the load demand of the buildings of the HTI campus as shown in Figure 7. The daily load demand for the HTI campus, consisting of 24 hours (scaled to 24 seconds in simulation time) was measured at the PCC before integrating the PV systems and the storage system. Knowing the load demand of HTI at these times gave a clear idea about how much power from PV systems and storage system were needed to cover the whole or the part of the HTI load demand according to stakeholders' desires. 


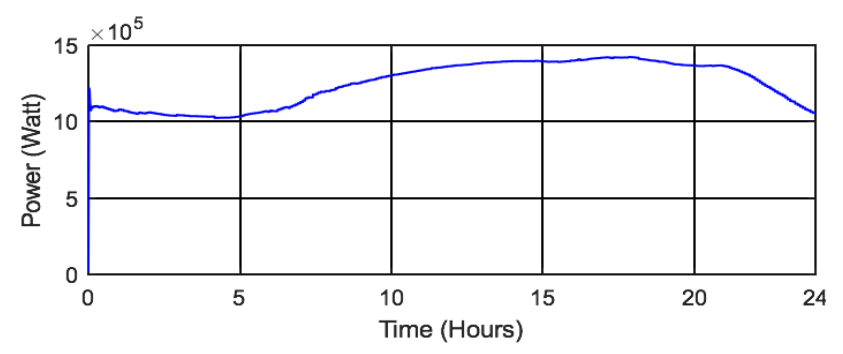

Figure 7. Load demand of the HTI campus

To test the performance of the new strategy that was mentioned in above, the overvoltage needed to be presented. Therefore, the power flow was reversed from HTI's MG to the main grid. The HTI load demand was less than the generated power from the PV systems and the storage system. Therefore, the load demand was selected as low peak demand during the period of Jan 2017 to Jan 2018 according to the load demand data for each building. High reversed power occurred during the10 to 15 second period, because solar irradiation goes up during this period. Meanwhile, the reversed power decreased during the 5 to 20 second period since the solar irradiation goes down.

\subsection{Overvoltage prevention result and discussion}

A new strategy was developed to secure the MG operation against overvoltage issues. The performance of this strategy was tested under varying solar irradiation. Prevention of overvoltage issues by using an energy storage system was the first option. Overvoltage was prevented before it crossed the allowable range of 1.05 p.u when the storage system observed required reversed power from the $\mathrm{MG}$ as demonstrated in Figure 8. When a droop controller was used, the necessary reversed power was accurately observed by the storage system. Thus, overvoltage was successfully prevented, and the MG worked safely.

In case the battery had been fully charged at SOC > 95\%, it would be impossible to observe the surpluses of power from the MG. Therefore, the power generations of two PVs are curtailed when the overvoltage reaches 1.05 p.u. The dashed line in Figure 9 represents the measured voltage at the critical bus which is about $1.1 \mathrm{pu}$, while the solid line displays prevention of overvoltage when the voltage reaches 1.05 p.u at the 10 second period.

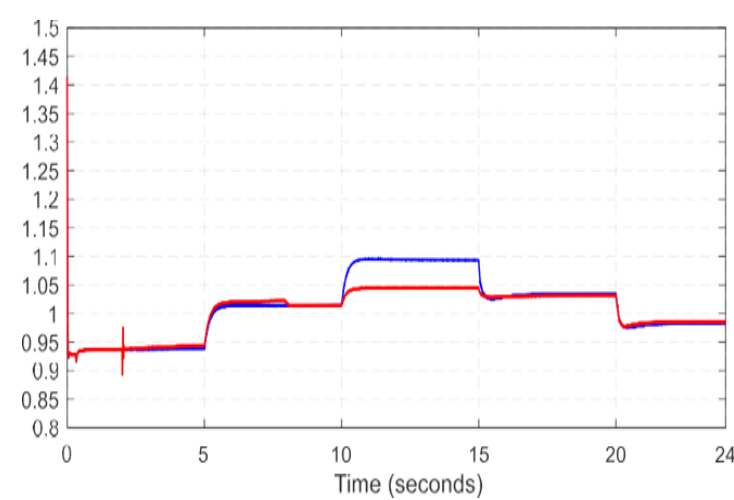

Figure 8. comparing voltage before and after prevention

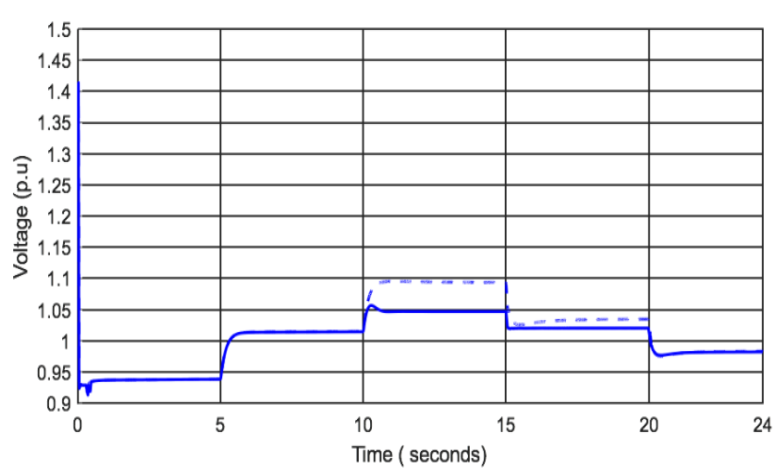

Figure 9. Prevention overvoltage by curtailed power of PVs

\section{CONCLUSION}

The design and operation of an HTI's MG were introduced in this work, which can make the HTI's distribution system more robust, reliable, and resilient against weather disasters or technical issues. If this project is adopted, the costs of consumed power should be reduced. The electrical distribution system of the HTI campus was analyzed. To secure the operation of the proposed MG against overvoltage issues, a new simple strategy of managing the storage system and PV generation was proposed and studied. This study 
provides a foundation to design the MG for the Hawija Technical Institute. The MG can help reduce emissions and protect the environment. HTI's MG project can become a demo for students who are interested in the study of renewable energy and microgrid.

\section{REFERENCES}

[1] J. Wang, C. Zhao, A. Pratt and M. Baggu, "Design of an advanced energy management system for microgrid controller uisng a state machine," Applied Energy, vol. 228, pp. 2407-2421, 2018.

[2] K. Mentesidi, et al., "Implementation of a Microgrid Model for DER Integration in Real-Time Simulation Platform," IEEE 23rd International Symposium on Industrial Electronics (ISIE), pp. 2274-2279, Jul 2014.

[3] Gilbert M Bokanga, Atanda Raji, Mohammed TE Kahn, "Design of a low voltage DC microgrid system for rural electrification in South Africa," Journal of Energy in Southern Africa, vol 25, no. 2, pp. 9-12. May 2014.

[4] I Alhamrouni, MK Rahmat, FA Ismail, M Salem, A Jusoh, T Sutikno, "Design and development of SEPIC DC-DC boost converter for photovoltaic application," International Journal of Power Electronics and Drive System (IJPEDS), vol. 10, no. 1, 406-413, Mar 2019.

[5] I Alhamrouni, MA Hairullah, NS Omar, M Salem, A Jusoh, T Sutikno. "Modelling and design of PID controller for voltage control of AC hybrid micro-grid," International Journal of Power Electronics and Drive System (IJPEDS), vol. 10, no. 1, pp. 151-159, Mar 2019.

[6] Salem, M., Jusoh, A., Idris, N.R.N., Sutikno, T. and Abid, I. "ZVS full bridge series resonant boost converter with series-connected transformer," International Journal of Power Electronics and Drive Systems (IJPEDS), vol 8, pp.812-825. 2017.

[7] H. Wen, H. Yu and Y. Hu, "Modeling and analysis of coordinated control strategies in AC microgrid," 2016 IEEE International Conference on Renewable Energy Research and Applications (ICRERA), Birmingham, pp. 702-707, 2016.

[8] Zaid Hussein, A. Abdullah Khalid, A. Amer Tayes, S.“ modeling solar modules performance under temperature and solar radiation of Western Iraq," International Journal of Power Electronics and Drive System (IJPEDS), vol. 9, no. 4, pp. 1842-1850, Dec 2018.

[9] Mohammed Q. Taha, Qusay H. Eesse and Salih Mohammed Salih, "Mathematical modeling of different photovoltaic modules", Journal of telecommunications, vol. 11, no. 2, pp. 59-64, Dec 2011.

[10] A. G. Garganeev, R. Aboelsaud, and A. Ibrahim, "A Novel Predictive Control Algorithm For Autonomous Power Supply Systems," in Proceedings of the 4th International Conference on Frontiers of Educational TechnologiesICFET '18, pp. 170-175, 2018.

[11] M. S. Sadabadi, Q. Shafiee, and A. Karimi, "Plug-and-play voltage stabilization in inverter-interfaced microgrids via a Robust Control Strategy," IEEE Trans. Control Syst. Technol., vol. 25, no. 3, pp. 781-791, May 2017.

[12] Omar Mohammed Benaissa, Samir Hadjeri, Sid Ahmed Zidi "Modelingand Simulation of Grid Connected PV Generation System Using Matlab/Simulink" International Journal of Power Electronics and Drive System (IJPEDS), vol. 8, no. 1, pp. 392-401, 2017.

[13] S. Obukhov, A. Ibrahim, and R. Aboelsaud, "Maximum power point tracking of partially shading PV system using particle swarm optimization," in Proceedings of the 4th International Conference on Frontiers of Educational Technologies - ICFET '18, pp. 161-165, 2018.

[14] S. G. Malla and C. N. Bhende, "Voltage control of stand-alone wind and solar energy system International Journal of Power Electronics and Drive System (IJPEDS), vol. 56, pp. 361-373, 2014.

[15] A. W. N. Husna, S. F. Siraj, and M. Z. Ab Muin, "Modeling of DC-DC converter for solar energy system applications," in 2012 IEEE Symposium on Computers and Informatics, ISCI 2012, 2012.

[16] K. M. Priyadharshini, S. Srinivasan, C. Srinivasan "Detection of power quality disturbances in micro grid connected power system," TELKOMNIKA Indonesian Journal of Electrical Engineering, vol. 14, no. 1, pp. 9-15, Apr 2015.

[17] Surender Reddy Salkuti, "Optimal operation management of Grid-Connected microgrids under uncertainty," Indonesian Journal of Electrical Engineering and Computer Science (IJEECS), vol. 16, no. 3, pp. 1163-1170, Dec 2019.

[18] H.Li et.al., "Optimal energy management for industrial microgrids with high-penetration renewables," Journal of Protection and control of Modern Power Systems, pp. 1-14, Apr 2017.

[19] Md. Asaduz-Zaman et.al., "Coordinated control of interconnected microgrid and energy storage System," International Journal of Electrical and Computer Engineering (IJECE), vol. 8, no. 6, pp. 4781-4789, Dec 2018.

[20] Sun Y, Huang W, Wang G, et al. Study of control strategy of DG based on nonlinear droop characteristic[C]//Electricity Distribution (CICED), 2012 China International Conference on. IEEE, 2012: 1-4.

[21] Ashabani S M, Mohamed Y A R I. General interface for power management of micro-grids using nonlinear cooperative droop control[J]. 2013.

[22] Vandoorn T L, De Kooning J D M, Meersman B, et al. Automatic Power-Sharing Modification of/Droop Controllers in Low-Voltage Resistive Microgrids[J]. Power Delivery, IEEE Transactions on, 2012, 27(4): 2318-2325.

[23] Zhang xiang-an, Zhang xin-chang. Study on adaptive master-slave control technology for isolated island operation of micro-grid[J]. Power System Protection and Control, 2014.

[24] L. J. Chen, Z. J. Wang, "Research of operation control of micro-grid based on improved droop control," Power System Protection and Control, vol. 44, no. 4, pp. 16-21, 2016.

[25] Y. Sun, G. Z. Shi, X. Li, W. B. Yuan, M. Su, H. Han and X. C. Hou, "An f-P/Q droop control in cascaded-type microgrid,” IEEE Trans on Power Systems, vol. 33, no.1, pp. 1136-1138, 2018. 


\section{BIOGRAPHIES OF AUTHORS}
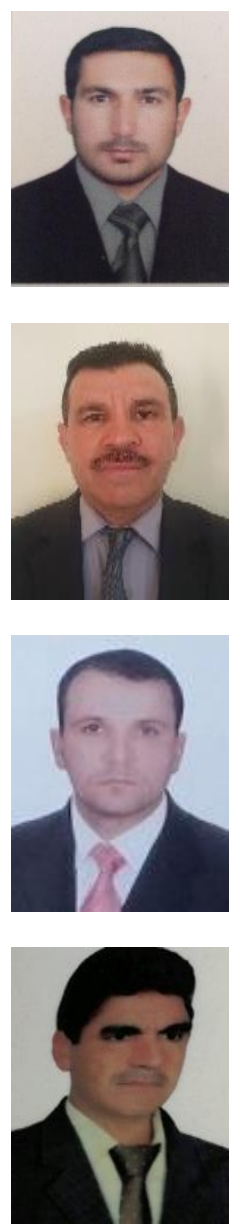

Zaid H. Ali, Currently, he is a lecturer at the Northern Technical University - Iraq. He holds MS.c degree from the University of New Haven, the USA in 2017 and received B.S. Degree in Electrical and Electronic Engineering from the University of Tikrit-Iraq in 2009. He is highly interested in renewable energy resources, Solar tracker systems, Wind turbines, Electrical power, Communication, Systems Engineering, Power Distribution systems, and Digital Signal Processing (DSP). He has published many papers in local and international journals and conferences.

Ziyaad H. Saleh, Ph.D in computer engineering, Currently, he is a Assist Prof. at Tikrit University - College of Petroleum and Minerals. He is Highly interested in renewable energy resources, communication systems His research experience includes nano-scale structures, artificial materials for novel electromagnetic applications. He has published many papers in international and local conferences and journals.

Raid W. Daoud, Bachelor college of Techniques computer engineering, Northern Technical University, Iraq, 2003, and the M.Sc from the same college in 2008. I have more than one paper published in different computer subjects, such as control and optical fiber.

\begin{abstract}
Ahmed H Ahmed, born in Iraq-Kirkuk May-14-1981. MSc in Mechanical Engineering, Tikrit University, College of Engineering, Tikrit, Salah Aldeen, Iraq 2008. His interesting researches in the field of Thermo-fluid systems, Renewable Energies, Nano-fluid applications, Composite Materials and Water Distillation methods. Asst. Prof. Ahmed is a faculty member at Mechanical Power Department, Northern Technical University, Mosul and he is a member of Iraqi Engineering Union.
\end{abstract}

